\title{
412 デビルスティックの持続回転運動のフィードバック制御 Feedback Control of Enduring Rotary Motion of Devil Stick
}

\author{
川井田 康礼（富士通） ○中浦 茂樹（東工大） \\ 大畠 龍介（東工大）正三平 満司（東工大） \\ Yasuyuki Kawaida, Fujitsu LTD. \\ Shigeki Nakaura, Ryusuke Ohata and Mitsuji Sampei \\ Tokyo Institute of Technology, 2-12-1 Oh-okayama, Meguro-ku, Tokyo
}

Devil stick is a kind of juggling as to control a floating stick (the center stick) by hitting or pushing with other sticks (the hand sticks). Various stick motions are performed by jugglers and some of them are studied as control problem.

The purpose of this paper is to rotate the center stick by only pushing with one hand stick. In other word, control objective is to maintain the position and the angular velocity of the center stick.

The control strategy in this paper is as follows. To begin with, some states are controlled by output zeroing control. The output function is derived from observing the motion of good jugglers. But there are two problems in this strategy. First, since the attitude angle of the center stick is in unobservable subspace, the angular velocity can't be controlled. Secondly, the direction of the input force isn't considered. For the first problem, by solving equations of the zero dynamics, it turns out that it is possible to stabilize the angular velocity by changing the contact point of the center stick and the hand stick. For the second one, the analytical result shows that the required force depends on the angular velocity. Some numerical simulations show the usefulness of the proposed strategy.

Key Words: Devil stick, Juggling, Zero dynamics, Enduring rotary motion

\section{1 はじめに}

デビルスティックとは，人間が手に持った棒（ハンドス ティック）で空中に浮いている棒（センタースティック） を操る曲芸の一種である.この種の芸としては, 両手に 持ったハンドスティックでセンタースティックを押す，ま たは吒くことによりセンタースティックを落下させないア

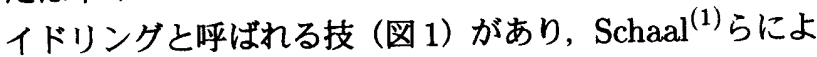
る研究では実験的に検証されている. 本研究ではプロペ ラと呼ばれる技（図 2）で，片手に持ったハンドスティッ クでセンタースティックを押すことでセンタースティック を回転させ続けるような運動の実現，つまりセンタース ティックの位置と角速度を制御することを目指している. 押す力だけで制御を行うことは, 制御入力に大きな制限 があることを意味し，非常に困難な問題である.

本論文の構成は以下の通りである， 2 節において，デ ビルスティックをモデル化し, 状態方程式を導出する. さ らにスティック間の接触に関し，いくつかの仮定を設定す る. 3 節では, デビルスティックを回転させ続けるための 制御目標を述べる. 4 節では, 人間がデビルスティックを 操作する様子を観察することにより得られた出力関数に 対し, 出力零化制御の効果をシミュレーションにより確 認する.さらに，構成したシステムにおける不可観測な 状態に対し, zero dynamics の解析を行うことで, 望まし い挙動を示すための条件を導出する. 5 節では, 得られ た解析結果を検証するための実験装置に関し簡単に述べ, 最後に 6 節において本論文をまとめている.
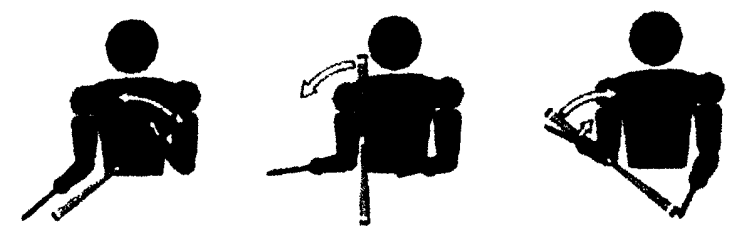

Fig. 1: Idling motion
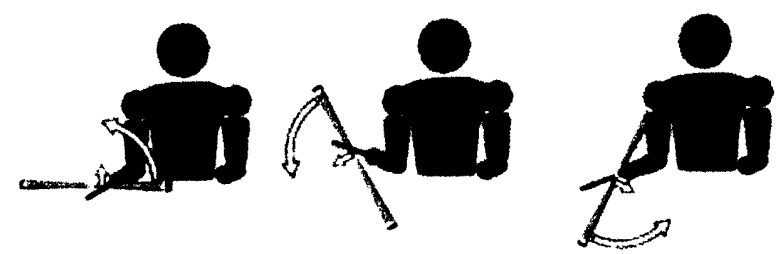

Fig. 2: propeller motion

\section{2 デビルスティックのモデル}

本論文では, 図 3 のようなデビルスティックのモデル を考える. センタースティックは鈶直平面内で動作する ものとし, その重心の位置を極座標で $(r, \theta)$, 姿勢角を $\phi$ で表す.ハンドスティックからセンタースティックに加え る力を $\boldsymbol{F}=\left[F_{t}, F_{n}\right]^{T}=\left[F_{r}, F_{\theta}\right]^{T}$ とする.

\section{1 センタースティックとハンドスティックの 接触}

センタースティックとハンドスティックが接触している ときに，以下の仮定が成り立っているとする. 


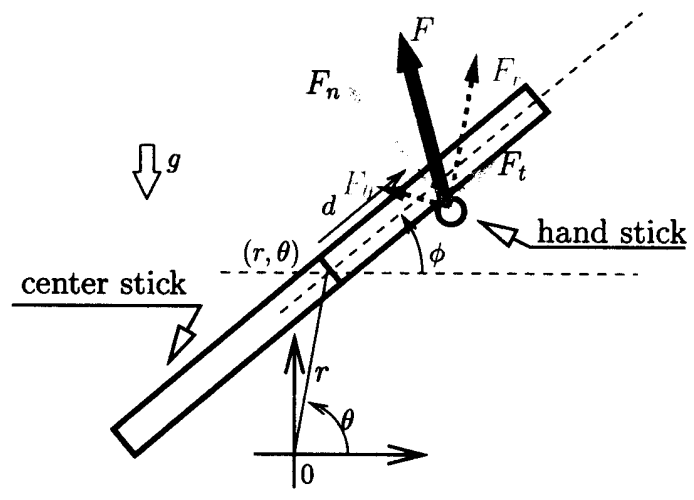

Fig. 3: Devil stick model on the vertical plane

Table 1: Parameter of the devil stick

$\begin{array}{ccl}(r, \theta) & : & \begin{array}{l}\text { Position of the center of gravity of } \\ \text { the center stick in the polar coordinate }\end{array} \\ \phi & : & \text { Attitude angle of center stick } \\ d & : & \begin{array}{l}\text { Position of the contact point from } \\ \text { the center of gravity of the center stick }\end{array} \\ \boldsymbol{F} & : \quad \text { Force applied by the center stick } \\ F_{t}, F_{n} & : \quad(t, n) \text { direction's component of } \boldsymbol{F} \\ F_{r}, F_{\theta} & : & (r, \theta) \text { direction's component of } \boldsymbol{F}\end{array}$

仮定 1 接触点での静止摩擦力は十分大きく，ハンドス ティックは横骬りしない.

仮定 2 センタースティックの回転に伴い, 転がりによっ て接触点が変化する.

仮定 2 より, センタースティックの重心から見た接触点の 位置 $d$ はセンタースティックの姿勢角 $\phi$ に依存しており, ハンドスティックの半径を $\rho$ とすると以下の関係式が成 り立つ。

$$
d(\phi)=-\rho \phi+d_{0}
$$

ここで, $d_{0}$ は初期接触位置とする.

本研究の目的は, センタースティックを回転させ続ける ことであり，その場合 $\phi$ は増加し続けることになる.こ のとき, $(1)$ より $d(\phi)$ は発散してしまう. 人間がセンター スティックを操る際, $d(\phi)$ の発散を防ぐために「センター スティックが 1 回転する度にハンドスティックをセンター スティックから離し, ハンドスティックの位置を初期位置 の近くに戻す」という動作を行う.この動作により，接 触点が発散することなく, センタースティックを回転させ 続けることが可能となる. そこで，この動作を簡単化す ることで，次の仮定をおくことにする.

仮定 3 センタースティックが 1 回転する（ $\phi$ が $2 \pi$ 增加 する）度に，接触点が瞬間的に元の位置に戻る.

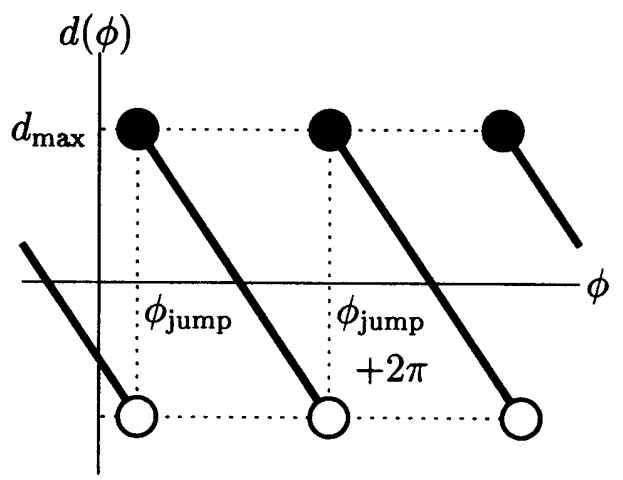

Fig. 4: The relationship between $\phi$ and $d(\phi)$

Table 2: Physical parameter

\begin{tabular}{lll}
\hline$m$ & $:$ & Mass of the center stick \\
$J$ & $:$ & Moment of inertia of the center stick \\
$\rho$ & $:$ & Radius of the hand stick \\
$g$ & $:$ & Acceleration of gravity \\
\hline
\end{tabular}

仮定 3 より， $\phi=\phi_{\text {jump }}$ の僢間に $d=d_{\max }$ に戻るとする と, $d(\phi)$ と $\phi$ の関係は

$$
\left\{\begin{array}{c}
d(\phi)=-\rho\left(\phi-\phi_{\text {jump }}\right)+d_{\max } \\
\left(\phi_{\text {jump }} \leq \phi<\phi_{\text {jump }}+2 \pi\right) \\
d(\phi+2 \pi)=d(\phi)
\end{array}\right.
$$

で表すことができ，その様子を図 4 に示す.

\section{2 状態方程式}

センタースティックの重心位置に関して, 表 2 の物理 パラメータの元, 極座標での運動方程式を導出する. $r$ 方 向, $\theta$ 方向の加速度をそれぞれ $a_{r}, a_{\theta}$ とすると, 以下の 式が成り立つ.

$$
\begin{aligned}
& a_{r}=\ddot{r}-r \dot{\theta}^{2} \\
& a_{\theta}=2 \dot{r} \dot{\theta}+r \ddot{\theta}
\end{aligned}
$$

これら $a_{r}, a_{\theta}$ は, $\boldsymbol{F}$ の分力 $F_{r}, F_{\theta}$ により

$$
\begin{aligned}
& a_{r}=\frac{F_{r}}{m}-g \sin \theta \\
& a_{\theta}=\frac{F_{\theta}}{m}-g \cos \theta
\end{aligned}
$$

と表すことができる. 幾何学的に, $F_{r}, F_{\theta} と F_{t}, F_{n}$ の間 には

$$
\left[\begin{array}{l}
F_{r} \\
F_{\theta}
\end{array}\right]=\left[\begin{array}{rr}
\cos (\theta-\phi) & \sin (\theta-\phi) \\
-\sin (\theta-\phi) & \cos (\theta-\phi)
\end{array}\right]\left[\begin{array}{l}
F_{t} \\
F_{n}
\end{array}\right]
$$


の関係がある．以上より，(5)(6)(7) を用いて $(3)(4)$ を書 き直すことで

$$
\begin{aligned}
& \ddot{r}=r \dot{\theta}^{2}-g \sin \theta+\frac{\cos (\theta-\phi)}{m} F_{t}+\frac{\sin (\theta-\phi)}{m} F_{n} \\
& \ddot{\theta}=-\frac{2 \dot{r} \dot{\theta}}{r}-\frac{g \cos \theta}{r}-\frac{\sin (\theta-\phi)}{r m} F_{t}+\frac{\cos (\theta-\phi)}{r m} F_{n}
\end{aligned}
$$

のような運動方程式が得られる. また，センタースティッ クの姿勢角 $\phi$ に関する運動方程式は以下のようになる.

$$
\ddot{\phi}=\frac{d(\phi) F_{n}}{J}
$$

(8)(9)(10) をまとめ, 状態と入力を

$$
\begin{aligned}
& \boldsymbol{x}=\left[\begin{array}{llllll}
r & \theta & \phi & \dot{r} & \dot{\theta} & \dot{\phi}
\end{array}\right]^{T} \\
& \boldsymbol{u}=\boldsymbol{F}=\left[\begin{array}{ll}
F_{t} & F_{n}
\end{array}\right]^{T}
\end{aligned}
$$

と選ぶことで，以下のような非線型状態方程式を導出す ることができる.

$$
\begin{array}{rl}
\dot{\boldsymbol{x}} & =f(\boldsymbol{x})+G(\boldsymbol{x}) \boldsymbol{u} \\
f(\boldsymbol{x}) & =\left[\begin{array}{c}
\dot{r} \\
\dot{\theta} \\
\dot{\phi} \\
r \dot{\theta}^{2}-g \sin \theta \\
-\frac{2 \dot{\varphi} \dot{\theta}}{r}-\frac{g \cos \theta}{r}
\end{array}\right] \\
0 & 0 \\
0 & 0 \\
0 & 0 \\
g(\boldsymbol{x}) & =\left[\begin{array}{cc}
\frac{\cos (\theta-\phi)}{m} & \frac{\sin (\theta-\phi)}{m} \\
-\frac{\sin (\theta-\phi)}{r m} & \frac{\cos (\theta-\phi)}{r m} \\
0 & \frac{d(\phi)}{J}
\end{array}\right]
\end{array}
$$

\section{3 制御目標}

本研究の目的は, センターステイックを持続的に回転さ せることであり, このためにはセンタースティックの位置 と角速度を制御する必要がある. 一方, 人間がセンター スティックを操る様子をみると

- 重心の位置が, ある点を中心に振動的に動く. その 際, 位置と姿勢角の振動周期が等しくなる.

・角速度が一定になる.

ということが観察できる. 1つめの項目について考察する と, 力を加える方向に制限があり, その方向が姿勢角 $\phi$ に 依存していることがわかる. そのため, 姿勢角の変化に伴 い, センタースティックの重心位置が振動的に変化してい

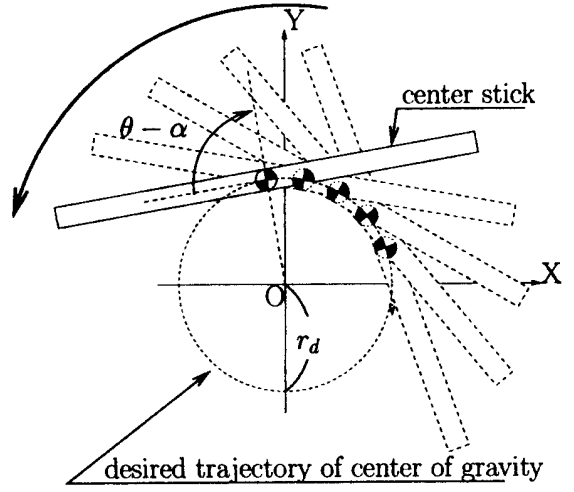

Fig. 5: Control objective

ると考えられる.よって，重心を原点に近づけるために， $\theta$ と $\phi$ の関係を一定に保つ, すなわち $\theta-\phi=$ constant とすることが望ましいと思われる.

以上より, センタースティックの持続回転を実現するた めには,

1. 重心の原点からの距離: $r$

2. 重心位置の偏角と姿勢角の差: $\theta-\phi$

3. 姿勢角の角速度: $\dot{\phi}$

を制御する必要がある．まず，重心の位置 $r$ に関しては， 図 5 のように目標軌道半径 $r_{d}$ に追従させることを考える. 次に, $\theta-\phi$ をある定数 $\alpha$ に渐近させる. 最後に, 角速 度 $\dot{\phi} に$ 関しては制御目標には加えず，次節において zero dynamics の解析を行うこととする.

\section{4 シミュレーション}

\section{1 出力零化制御による持綍回転通動の実現}

3 節に基づき，以下のような出力関数を設定する.

$$
\boldsymbol{y}=\left[\begin{array}{l}
y_{1} \\
y_{2}
\end{array}\right]=\left[\begin{array}{c}
r_{d}-r \\
\alpha-(\theta-\phi)
\end{array}\right]
$$

ф は出力関数には含めずに, zero dynamics の解析を行う ことで, 安定になるための条件を導出することにする.

まず (14) を入出力線型化することで, 以下のような線 型な状態方程式を得ることができる.

$$
\begin{aligned}
\dot{\boldsymbol{\xi}} & =A \boldsymbol{\xi}+B \boldsymbol{v} \\
\dot{\boldsymbol{\eta}} & =\zeta_{1}(\boldsymbol{\xi}, \boldsymbol{\eta})+\zeta_{2}(\boldsymbol{\xi}, \boldsymbol{\eta}) \boldsymbol{v} \\
\dot{\boldsymbol{y}} & =C \boldsymbol{\xi}
\end{aligned}
$$

$$
\begin{aligned}
& \boldsymbol{\xi}=\left[\begin{array}{llll}
\xi_{1} & \xi_{2} & \xi_{3} & \xi_{4}
\end{array}\right]^{T} \\
& =\left[\begin{array}{llll}
r_{d}-r & \alpha-(\theta-\phi) & -\dot{r} & -(\dot{\theta}-\dot{\phi})
\end{array}\right]^{T} \\
& \eta=\left[\begin{array}{ll}
\eta_{1} & \eta_{2}
\end{array}\right]^{T}=\left[\begin{array}{ll}
\phi & \dot{\phi}
\end{array}\right]^{T} \\
& \boldsymbol{v}=\ddot{\boldsymbol{y}}
\end{aligned}
$$


Table 3: Parameter values

\begin{tabular}{|c|c|c|c|}
\hline$m$ & $: 0.2[\mathrm{~kg}]$ & $r_{d}$ & $: 0.05[\mathrm{~m}]$ \\
\hline$J$ & $: \quad 0.01\left[\mathrm{~kg} \mathrm{~m}^{2}\right]$ & $\alpha$ & $: \quad-\frac{1}{2} \pi[\mathrm{rad}]$ \\
\hline$\rho$ & $: \quad 0.03[\mathrm{~m}]$ & $\phi_{\mathrm{j} u m p}$ & $: \quad \frac{7}{6} \pi[\mathrm{rad}]$ \\
\hline$g$ & $: \quad 9.8\left[\mathrm{~m} / \mathrm{s}^{2}\right]$ & $d_{\max }$ & $: \quad \frac{1}{2} \rho \pi[\mathrm{m}]$ \\
\hline
\end{tabular}

$$
\begin{aligned}
A & =\left[\begin{array}{ll}
O^{2 \times 2} & I^{2 \times 2} \\
O^{2 \times 2} & O^{2 \times 2}
\end{array}\right] \\
B & =\left[\begin{array}{l}
O^{2 \times 2} \\
I^{2 \times 2}
\end{array}\right] \\
C & =\left[\begin{array}{ll}
I^{2 \times 2} & O^{2 \times 2}
\end{array}\right] \\
\zeta_{1}(\boldsymbol{\xi}, \boldsymbol{\eta}) & =\left[\begin{array}{c}
\eta_{2} \\
\frac{i}{h}
\end{array}\right] \\
\zeta_{2}(\boldsymbol{\xi}, \boldsymbol{\eta}) & =\left[\begin{array}{ll}
0 & 0 \\
j & \frac{k}{h}
\end{array}\right] \\
h & =J-d\left(\eta_{1}\right) m\left(r_{d}-\xi_{1}\right) \cos \left(\alpha-\xi_{2}\right) \\
i & =d\left(\eta_{1}\right) m\left\{g \cos \eta_{1}-\left(-\xi_{4}+\eta_{2}\right)\left(2 \xi_{3} \cos \left(\alpha-\xi_{2}\right)\right.\right. \\
j & \left.\left.=-d\left(\eta_{1}\right) m \sin \left(\alpha-\xi_{4}+\eta_{2}\right)\left(r_{d}-\xi_{1}\right) \sin \left(\alpha-\xi_{2}\right)\right)\right\} \\
k & =-d\left(\eta_{1}\right) m\left(r_{d}-\xi_{1}\right) \cos \left(\alpha-\xi_{2}\right)
\end{aligned}
$$

上記のシステムに対し, 表 3 のパラメータを用いて状態 フィードバックによる出力雾化のシミュレーションを行っ た結果を図 6 に示す. 出力である $\xi_{1}, \xi_{2}$ は 0 に収束して いるが, 角速度 $\dot{\phi}=\eta_{2}$ のふるまいは, $\phi_{\mathrm{jump}}, d_{\mathrm{max}}$ に強 く依存していることがわかる.

\section{2 角速度の安定化}

本節では, zero dynamicsの解析を行うことで，角速度 ф が安定となる条件を導出することを試みる. (19), (23), (28), (29) より, zero dynamics は以下のようになる.

$$
\frac{d}{d t}\left[\begin{array}{c}
\phi \\
\dot{\phi}
\end{array}\right]=f_{\phi}(\phi, \dot{\phi})=\left[\begin{array}{c}
\dot{\phi} \\
\frac{d(\phi) m\left(g \cos \phi-r_{d} \dot{\phi}^{2} \sin \alpha\right)}{J-d(\phi) m r_{d} \cos \alpha}
\end{array}\right]
$$

(30) を簡略化するために， $\alpha$ を固定することを考える. 図 7 は, 出力が零化された状態を示している.この状態で回 転を続けるとき, 重心の原点からの距離 $r$ を保つために 遠心力と釣り合うだけの力を加える必要がある. そのた めに, $\alpha=-\pi / 2$ とすることで常に回転の中心方向に力 を加えることができ, 制御目標を達成するために適して いると思われる. そこで, $\alpha=-\pi / 2$ と固定すると, 以
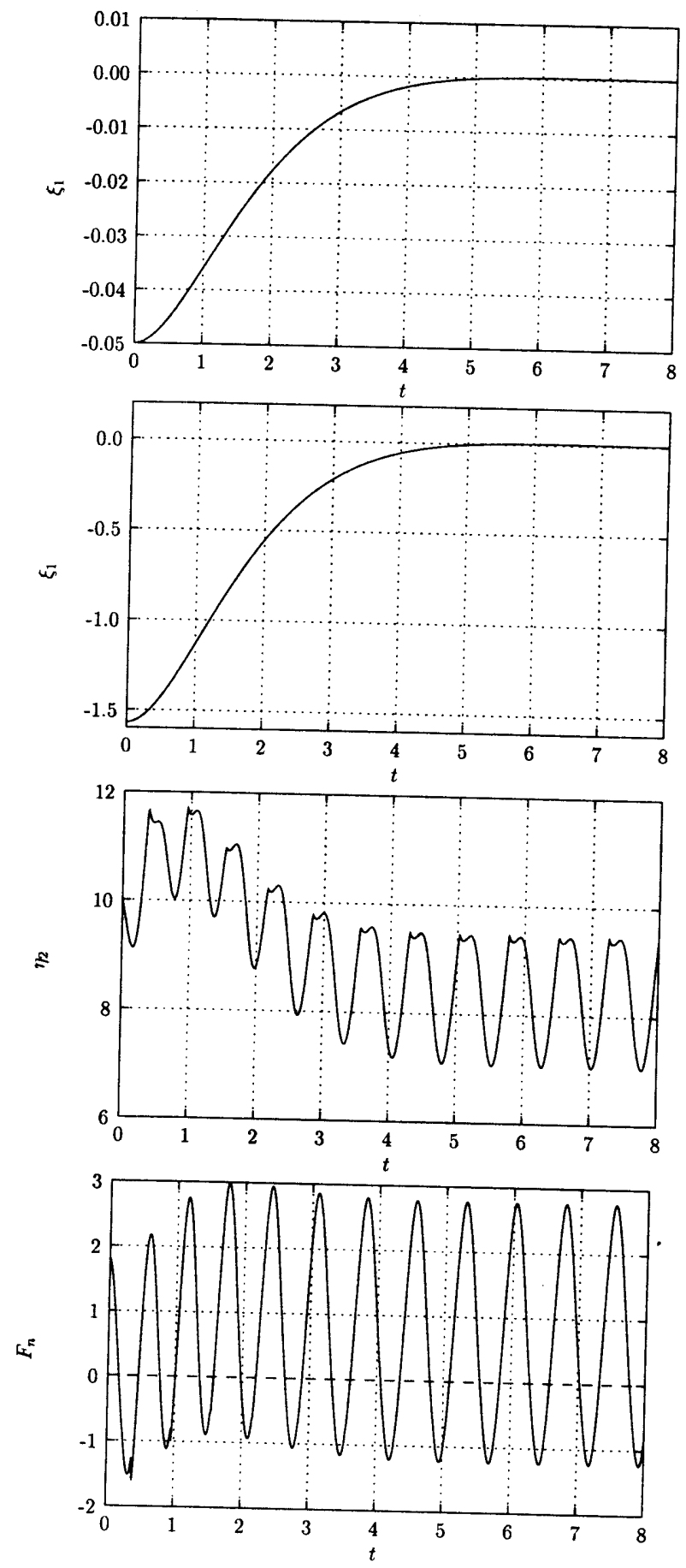

Fig. 6: The results of simulation

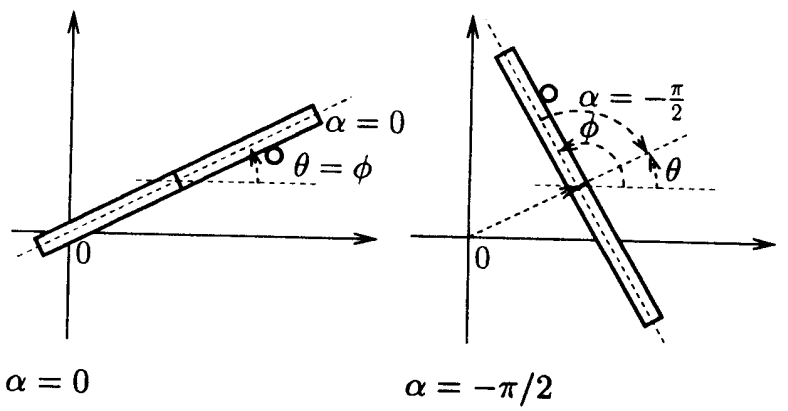

Fig. 7: Physical meaning of $\alpha$ 
下の簡略化された zero dynamics を得ることができる.

$$
\frac{d}{d t}\left[\begin{array}{c}
\phi \\
\dot{\phi}
\end{array}\right]=f_{\phi}(\phi, \dot{\phi})=\left[\begin{array}{c}
\dot{\phi} \\
\frac{d(\phi) m\left(g \cos \phi+r_{d} \dot{\phi}^{2}\right)}{J}
\end{array}\right]
$$

zero dynamics を解析するために, 以下の変数変換を 行う.

$$
\phi^{\prime}=\phi-2 n \pi, \quad\left(\phi_{\mathrm{jump}} \leq \phi^{\prime}<\phi_{\mathrm{jump}}+2 \pi\right)
$$

$\dot{\phi}^{\prime}=\dot{\phi}, \ddot{\phi}^{\prime}=\ddot{\phi}$ の関係を用いることで, (31)(2) は

$$
\begin{aligned}
\ddot{\phi}^{\prime} & =\frac{d\left(\phi^{\prime}\right) m\left(g \cos \phi^{\prime}+r_{d} \dot{\phi}^{\prime 2}\right)}{J} \\
d\left(\phi^{\prime}\right) & =\rho\left(\phi^{\prime}-\phi_{\text {jump }}\right)+d_{\max }
\end{aligned}
$$

のように表すことができ，(34) を(33) に代入することで 次の $\phi^{\prime}$ に関する微分方程式を得ることができる.

$$
\begin{aligned}
\ddot{\phi}^{\prime} & =\frac{\left(-\rho\left(\phi^{\prime}-\phi_{\mathrm{jump}}\right)+d_{\max }\right) m\left(g \cos \phi+r_{d} \dot{\phi}^{2}\right)}{J} \\
& =-a_{1}\left(\phi^{\prime}-a_{2}\right)\left(g \cos \phi^{\prime}+r_{d} \dot{\phi}^{2}\right)
\end{aligned}
$$

ただし， $a_{1}, a_{2}$ は以下で定義するものとする.

$$
a_{1}=\frac{m \rho}{J}, \quad a_{2}=\phi_{\mathrm{jump}}+\frac{d_{\max }}{\rho}
$$

$\phi^{\prime}$ を解くために， $\dot{\phi}^{\prime 2}=P$ とおき，両辺を微分する.

$$
\begin{aligned}
\frac{d \dot{\phi}^{\prime 2}}{d t} & =\frac{d P}{d t} \\
\Leftrightarrow \quad 2 \dot{\phi}^{\prime} \ddot{\phi}^{\prime} & =\frac{d \phi^{\prime}}{d t} \frac{d P}{d \phi^{\prime}} \\
& =\dot{\phi}^{\prime} \frac{d P}{d \phi^{\prime}} \\
\Leftrightarrow \quad \ddot{\phi}^{\prime} & =\frac{1}{2} \frac{d P}{d \phi^{\prime}} \quad\left(\dot{\phi}^{\prime} \neq 0\right)
\end{aligned}
$$

(37) と $\dot{\phi}^{\prime 2}=P$ を(35) に代入して整理することで

$$
\frac{1}{2} \frac{d P}{d \phi^{\prime}}=-a_{1}\left(\phi^{\prime}-a_{2}\right)\left(g \cos \phi^{\prime}+r_{d} P\right)
$$

を得ることができ,これは $P$ を $\phi^{\prime}$ の関数として以下の ように解くことができる(2).

$$
\begin{aligned}
& P\left(\phi^{\prime}\right) \\
& \quad=e^{-a_{1} r_{d} \phi^{\prime}\left(\phi^{\prime}-2 a_{2}\right)} \int_{C_{1}}^{\phi^{\prime}} \frac{-2 g a_{1}\left(\tau-a_{2}\right) \cos \tau}{e^{-a_{1} r_{d} \tau\left(\tau-2 a_{2}\right)}} d \tau
\end{aligned}
$$$$
\text { ( } C_{1} \text { : constant) }
$$

$\phi^{\prime}$ は $\phi_{\text {jump }} \leq \phi^{\prime}<\phi_{\text {jump }}+2 \pi$ を満たすことを考慮して,

$$
\begin{aligned}
p_{k}^{2} & =P\left(\phi_{\text {jump }}\right) \\
p_{k+1}^{2} & =\lim _{\phi^{\prime} \rightarrow \phi_{\text {jump }}+2 \pi} P\left(\phi^{\prime}\right) \\
& =P\left(\phi_{\text {jump }}+2 \pi\right)
\end{aligned}
$$

のような離散変数を定義すると, $p_{k}, p_{k+1}$ の関係は以下 のように表されることがわかる.

$$
\begin{aligned}
p_{k+1}^{2}= & \Lambda_{1} p_{k}^{2}+\Lambda_{2} \\
\Lambda_{1}= & e^{-4 \pi m r_{d}\left(\rho \pi-d_{\max }\right) / J} \\
\Lambda_{2}= & e^{-m r_{d}\left(\phi_{\mathrm{jump}}+2 \pi\right)\left(\rho\left(-\phi_{\mathrm{jump}}+2 \pi\right)-2 d_{\mathrm{max}}\right) / J} \times \\
& \int_{\phi_{\mathrm{jump}}}^{\phi_{\mathrm{jump}}+2 \pi}\left\{\frac{1}{e^{-m r_{d} \tau\left(\rho\left(\tau-2 \phi_{\mathrm{jump}}\right)-2 d_{\max }\right) / J} \times}\right. \\
& \left.\left(-2 g m\left(\rho\left(\tau-\phi_{\mathrm{jump}}\right)-d_{\max }\right) \cos \tau / J\right)\right\} d \tau
\end{aligned}
$$

ここで $p_{\infty}$ について考察するために $(42)$ を解くと, 以下 を得る。

$$
p_{\infty}^{2}= \begin{cases}\Lambda_{1}^{k}\left(p_{0}^{2}-\frac{\Lambda_{2}}{1-\Lambda_{1}}\right)+\frac{\Lambda_{2}}{1-\Lambda_{1}} & \left(\text { if } \Lambda_{1} \neq 0\right) \\ p_{0}^{2}+k \Lambda_{2} & \left(\text { if } \Lambda_{1}=1\right)\end{cases}
$$

(43) から $\Lambda_{1}>0$ であるから， $\Lambda_{1}$ に関し以下の 3 つの場 合が考えられる.

$0<\Lambda_{1}<1$ の堨合

このとき $p_{\infty}=\sqrt{\frac{\Lambda_{2}}{1-\Lambda_{1}}}$ となる. $\Lambda_{2} \geq 0$ のとき $p_{k}$ は実数に収束するが, $\Lambda_{2}<0$ のとき $p_{k}$ は虚数に収 束し，これは途中でセンタースティックが逆回転す ることを意味する.

$\Lambda_{1}>1$ の場合

$p_{0}=\sqrt{\frac{\Lambda_{2}}{1-\Lambda_{1}}}$ のときに全ての $k$ に対して $p_{k}=p_{0}$ と なるが，それ以外のときは発散する。

\section{$\Lambda_{1}=1$ の場合}

$\Lambda_{2}=0$ のときに全ての $k$ に対して $p_{k}=p_{0}$ となる.

$\Lambda_{2}<0$ のときにはセンタースティックが逆回転し,

$\Lambda_{2}>0$ のときには $p_{k}$ は発散する.

以上の考察より, センタースティックの角速度を安定に するためには, $0<\Lambda_{1}<1, \Lambda_{2}>0$ を満たす必要がある. $0<\Lambda_{1}<1$ となる条件は (43) より

$$
-4 \pi m r_{d}\left(\rho \pi-d_{\max }\right) / J<0
$$

であるが, $m, J, \rho, r_{d}$ が正值であることを考慮すると

$$
d_{\max }<\rho \pi
$$

となる. センタースティックとハンドスティックの接触点 $d(\phi)$ は $d_{\max }-2 \rho \pi<d(\phi) \leq d_{\max }$ の範囲を移動するた め, $d_{\max }<\rho \pi$ の場合には $d(\phi)$ は負の方に奇っているこ とになる. 一方 $\Lambda_{2}$ には積分項が含まれるため, 解析的に $\Lambda_{2}>0$ となる条件を求めることは困難である. そこで表 4 に示すパラメータを用いて数值的に $\Lambda_{2}$ を求めた結果を 図 8 に示す.これより，それぞれのパラメー夕の組に対 して, $\Lambda_{2}>0$ となるような $\phi_{\text {jump }}$ と $d_{\max }$ が存在するこ とが確認できる. 
Table 4: Parameters used in calculation of $\Lambda_{2}$

\begin{tabular}{|c|c|c|c|c|}
\hline \multicolumn{2}{|c|}{ parameter } & Fig.9(a) & Fig.9(b) & Fig.9(c) \\
\hline$m / J$ & {$\left[\mathrm{~m}^{-2}\right]$} & 6.0 & 20.0 & 60.0 \\
\hline$\rho$ & [m] & 0.009 & 0.03 & 0.09 \\
\hline$r_{d}$ & {$[\mathrm{~m}]$} & 0.015 & 0.05 & 0.15 \\
\hline
\end{tabular}

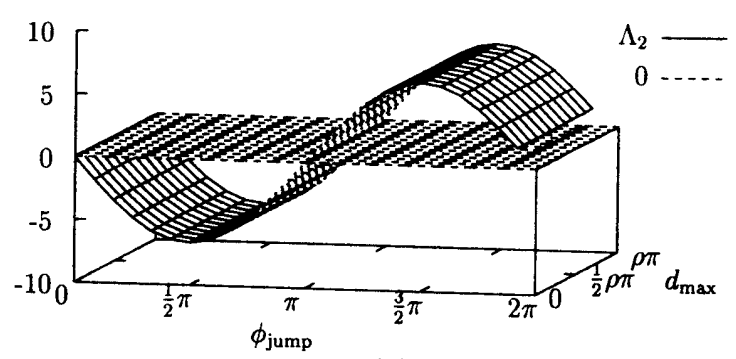

(a)

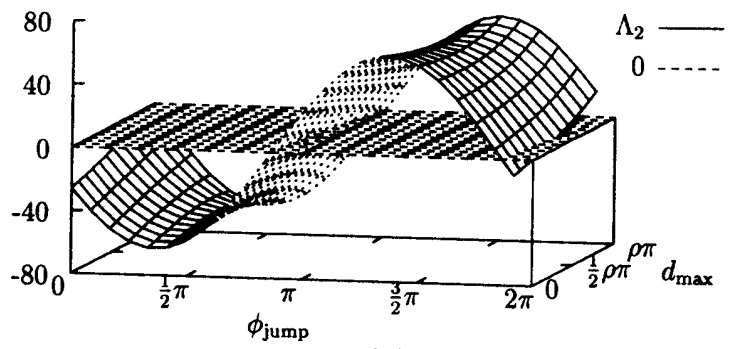

(b)

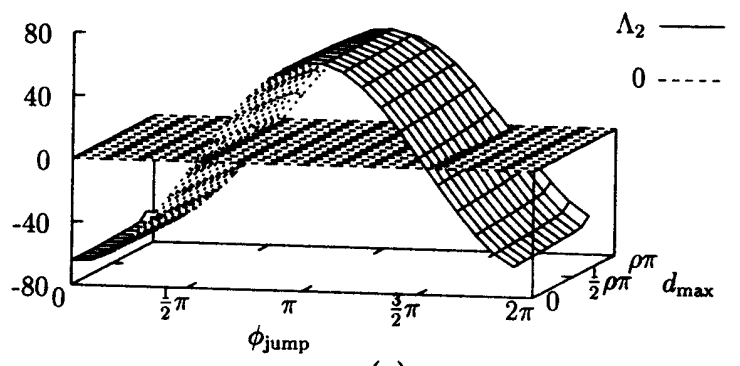

(c)

Fig. 8: variation of $\Lambda_{2}$

\section{5 実験装置の概要}

2 節において, センタースティックが 1 回転する度に接 触点が瞬間的に初期位置に戻ることを仮定した.しかし， 実験的にこの仮定を実現することは困難である，そこで， 前説までで議論してきたデビルスティックの持続回転運 動を実験的に検証するために，先の仮定の近似的な実現 として以下の 2 つの phase を考える.

phase 1 ハンドスティックを介してセンタースティック に力が加えられていて，ハンドスティックのまわり をセンタースティックが回転している状態.

phase 2 センタースティックは自由に移動できる，つま り，ハンドスティックからカは加わっておらず，八 ンドスティックはセンタースティックに沿って䯚る ことができる状態.

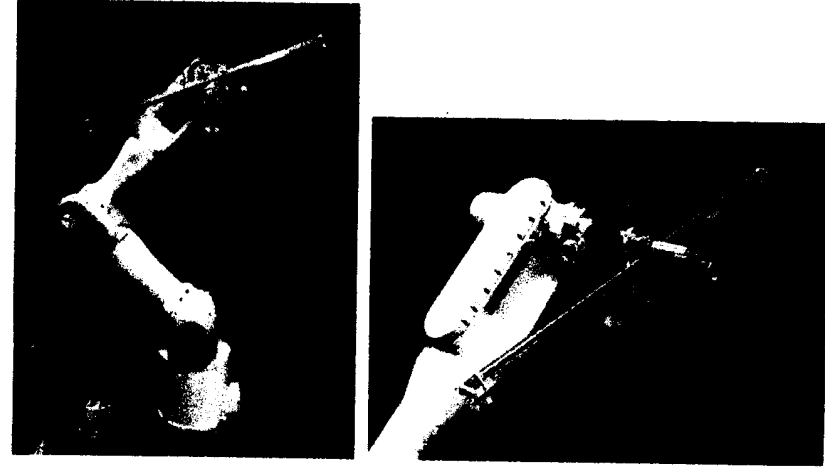

Fig. 9: Overview of experimental setup

phase 1 においては, センタースティックは持続回転す るように制御することができる.しかし， phase 2 におい てはセンタースティックは惰性で回転するのみである.

以上を踏まえ，本研究で製作した実験装置を図 9 に示 す. 2 つの phase の切り替えは, 空気圧によりハンドス ティックの摩擦状態を変化させることで寒現している. 今 後, センタースティックの持続回転を実験的に実現させる ことを試みていく予定である.

\section{6 まとめ}

本論文では, デビルスティックの持続回転運動の実現に 対し以下のような結果を得た。

・ 接触点に関する仮定のもとで, デビルスティックの 状態方程式の導出

・ 人間がデビルスティックを操作する様子の観察に基 ブいた出力関数の設定

- 出力零化による持続回転運動を数値シミュレーショ ンにより確認

- zero dynamics の解析によりセンタースティックの 角速度の振る舞いを考察し，安定な角速度を得るた めのパラメー夕を導出

- 実験的検証に向けての装置の製作

\section{文献}

(1) Stefan Schaal and Christopher G. Atkeson, Open Loop Stable Control Strategies for Robot Juggling, Proc. of IEEE International Conference on Robotics and Automation (1993), 913-918

(2) Kreyszig, Advanced Engineering Mathematics 8th edition, John Wiley \& Sons, Inc. (1999) 